\title{
Meet the New President of IUGS: Umberto Cordani
}

Prof. Umberto G. Cordani has been elected President of the International Union of Geological Sciences as of May 1, 1988. He replaces Prof. Eugen Seibold who had temporarily filled the gap left by the death in July 1987 of President William Hutchison.

Born in Italy in 1938, but a citizen of Brazil since 1960 , Prof. Cordani is Director of the Institute of Geosciences at the University of São Paulo, perhaps the largest and most productive geoscience research organization in South America. A USP graduate himself, Prof. Cordani is a member of the Brazilian Academy of Sciences, the Academy of Sciences of the State of São Paulo, and a member of editorial boards of several South American and intermational journals. He is the author of over 140 scientific books, papers and other publications, especially on geochronology, of which he is a pioneering leader in South America (see Profile in June 1985 issue of Episodes).

Prof. Cordani is well known for his active and wide-ranging participation in the international scientific community. He was a Vice-President of IUGS from 1984 and member of the IUGS Advisory Board for Research Development, until his election as President. He has also been a member of the IGCP Scientific Committee (1980-85), the Council of the International Association of Geochemistry and Cosmochemistry (1981-85), and the Bureau of the Inter-Union Commission on the Lithosphere (1981-85). Prof. Cordani also served as leader of IGCP Project 120 ("Magmatic Evolution of the Andes"), on the IUGS Sub-Commission of Geochronology, on the IAVCEI Working Group on Radiogenic Isotopes, and on the former International Geodynamics Project. He has been Visiting Professor in the Université Libre (Brussels), the Universidad de Chile (Santiago), University of Texas (Dallas), the University of Oxford, the University of California (San Diego) and the Universita degli Studi di Milano. Umberto Cordani and his wife Lisbeth have two children.

In a recent interview with Episodes, Prof. Cordani talked of his hopes for IUGS. He paid tribute to the many scientists around the world involved in one of the main tasks of the Union, the setting of international standards in geology, especially as regards stratigraphic boundaries and rock nomenclature. This work, he pointed out, can only be carried out in an international forum like IUGS. On the other hand, IUGS also encourages and provides support for projects on new aspects of earth sciences such as mineral deposit modelling, remote sensing, comparative planetology and microtectonics. Likewise, Prof. Cordani believes that both basic and applied research are important, though the former is closer to the main goals of IUGS. He points to the valuable work on applied geology carried out under IUGS affiliates such as the International Association of Engineering Geology, with its activities on urban geology and on landslides.

He sees as one of the main tasks ahead for IUGS to strengthen its national committees around the world and their links with the Union, a special concern also of Bill Hutchison. Another challenge is to find the best way to involve the geological sciences in the new interdisciplinary environmental science, such as embodied in the Global Change program recently launched by ICSU. These endeavours transcend IUGS and require closer links between geologists, geophysicists, biologists and ecologists, between IUGS, IUGG and other ICSU unions.

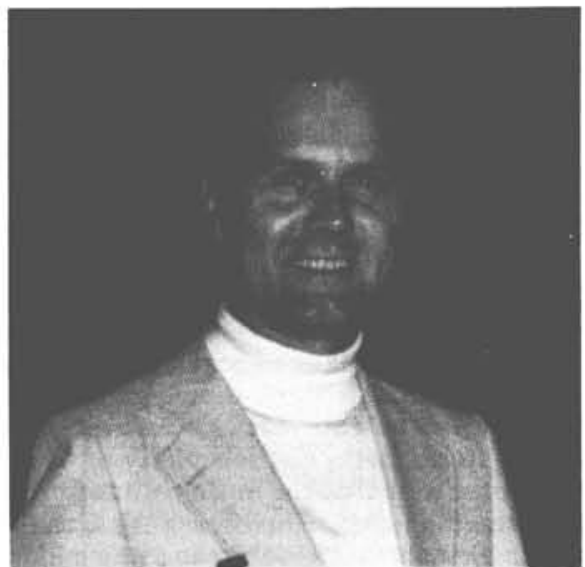

Prof. Cordani is the first IUGS President from the Third World, a significant change for the Union, which began as a European and North American initiative. He points out that geology is global and cannot be viewed only from the North. Important geological records can be preserved anywhere, and each regional setting is unique and must be studied from within. The tropical regions are obviously important, since they exhibit many distinct geological and geochemical processes at the surface that must be studied if we wish to consider a global earth system. On the other hand the development of science in the Third World cannot be accomplished alone, for the progress from one level of development to another requires international cooperation, as it does for economic and social improvements.

Prof. Cordani points with pride to the very rapid growth of the geological community in Brazil from 1960, when he was among the first graduating class of geologists, to the present number of 4000 to 5000 . Yet for the 140 million people of Brazil, a few thousand geologists in such a vast land are not really sufficient to meet local needs, and the contrast with the situation in the U.S.A. or even more so in the U.S.S.R. is marked. Moreover, the best scientists are so burdened with other duties that they have difficulty in working effectively.

Geology is certainly not known enough by the public, and if this is true in general the problem is dramatic in the Third World. Thus, geological education, he feels, should be one obvious priority area for IUGS, for example through its Commission on Geology Teaching and the Association of Geoscientists for International Development. Prof. Cordani welcomes suggestions for specific actions.

At the same time he recognizes the need for caution when adding more projects to the already very full program of IUGS. He would like to ensure that those projects already underway receive effective support rather than spreading the Union's limited resources among additional initiatives. Clearly, President Cordani is excited by the challenge of channelling through the work of the Union the enthusiasm of geoseientists around the world.

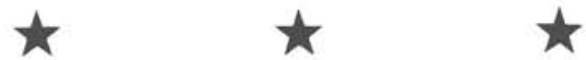

